\title{
Structural Reasons for the Nonlinear Optical Properties of KTP Family Single Crystals
}

\author{
Nataliya E. Novikova ${ }^{1, *}$, Nataliya I. Sorokina ${ }^{1}$, Igor A. Verin ${ }^{1}$, Olga A. Alekseeva ${ }^{1}$, \\ Ekaterina I. Orlova ${ }^{2}$, Valentina I. Voronkova ${ }^{2}$ and Michael Tseitlin ${ }^{3}$ \\ 1 Shubnikov Institute of Crystallography, Federal Scientific Research Centre "Crystallography and Photonics", \\ Russian Academy of Sciences, Moscow 119333, Russia; nsor@ns.crys.ras.ru (N.I.S.); \\ Krol@ns.crys.ras.ru (I.A.V.); olalex@crys.ras.ru (O.A.A.) \\ 2 Faculty of Physics, Moscow State University, Moscow 119991, Russia; agapova@polly.phys.msu.ru (E.I.O.); \\ voronk@polly.phys.msu.ru (V.I.V.) \\ 3 Crystal Growth Laboratory, Ariel University of Samaria, Ariel 40700, Israel; Michael.Tseitlin@raicol.com \\ * Correspondence: nata110565@mail.ru; Tel.: +7-499-135-3110
}

Received: 13 June 2018; Accepted: 7 July 2018; Published: 10 July 2018

\begin{abstract}
A brief review focuses on studies into the structural reasons for the nonlinear optical properties of crystals of the potassium titanyl phosphate family, performed at the Shubnikov Institute of Crystallography. Accurate X-ray diffraction data are discussed, providing evidence that the optical susceptibility of crystals is related not only to the alternation of long and short Ti-O bonds in the chains of $\mathrm{TiO}_{6}$ octahedra, but to the geometry of tetrahedral anions and the alkaline cation arrangement in the structure channels, as well. The contribution of each of the three structural components depends on the crystal composition.
\end{abstract}

Keywords: potassium titanyl phosphate; single crystals; nonlinear optical properties; accurate X-ray analysis

\section{Introduction}

Crystals of the potassium titanyl phosphate $\mathrm{KTiOPO}_{4}$ family (KTP) are materials of a special type, namely, ferroelectrics-superionic conductors. They exhibit high nonlinear susceptibility and stability to external effects over a wide temperature range. KTP crystals are widely used in nonlinear optical devices, in particular, for doubling and tuning the frequency of laser radiation [1-3]. They are employed as active elements in electrooptic modulators of solid-state lasers for parametric light generation and as waveguides in integrated optics [4-7].

For nonlinear optics applications, high-resistance $\left(\varrho \sim 10^{7}-10^{11} \Omega \mathrm{cm}\right)$ crystals with a low defect concentration are suitable. Therefore, obtaining large, optically pure crystals of the KTP family is a highly important technological concern [8]. Concurrently, the search for new compounds with nonlinear optical characteristics exceeding those of the pure (undoped) KTP crystals is ongoing. The search for compounds with improved nonlinear optical characteristics is carried out through the use of multiple isomorphous substitutions. As of this writing, the intensity of the second harmonic generation (SHG) signal is found to increase by a factor of 1.6 in $\mathrm{KTiOAsO}_{4}$ (KTA) crystals, which remain isostructural to KTP crystals with complete substitution of arsenic for phosphorus [9]. The SHG signal increases by $10 \%$ and $20 \%$ upon the partial ( $5 \%$ and $4 \%$ respectively) substitution of niobium for titanium [10-12], by a factor of approximately two upon the partial substitution of zirconium for titanium [13,14], and by 30-40\% in KTP crystals doped with hafnium [15].

The unique combination of physical properties derives from the specific features of the crystal structure of KTP (polar space group Pna2 $2_{1}$ [16] in the ferroelectric phase existing below $934{ }^{\circ} \mathrm{C}$ [17]). 
It is a rigid three-dimensional framework consisting of alternating vertex-sharing $\mathrm{TiO}_{6}$ octahedra and $\mathrm{PO}_{4}$ tetrahedra with channels running along the $c$ axis (Figure 1a). The channels contain cations of potassium or other alkali elements. The high ionic conductivity of KTP crystals is caused by vacancies at alkali element positions and diffusion of cations over these vacancies. Relaxation of potassium atoms, which is connected to the formation of alkali cation-vacancy dipoles, appears on the temperature-permittivity plot as a broad anomaly in a range from 200 to $700{ }^{\circ} \mathrm{C}$. The state of the cation sublattice has been shown to affect the ferroelectric properties of crystals of this family [18].

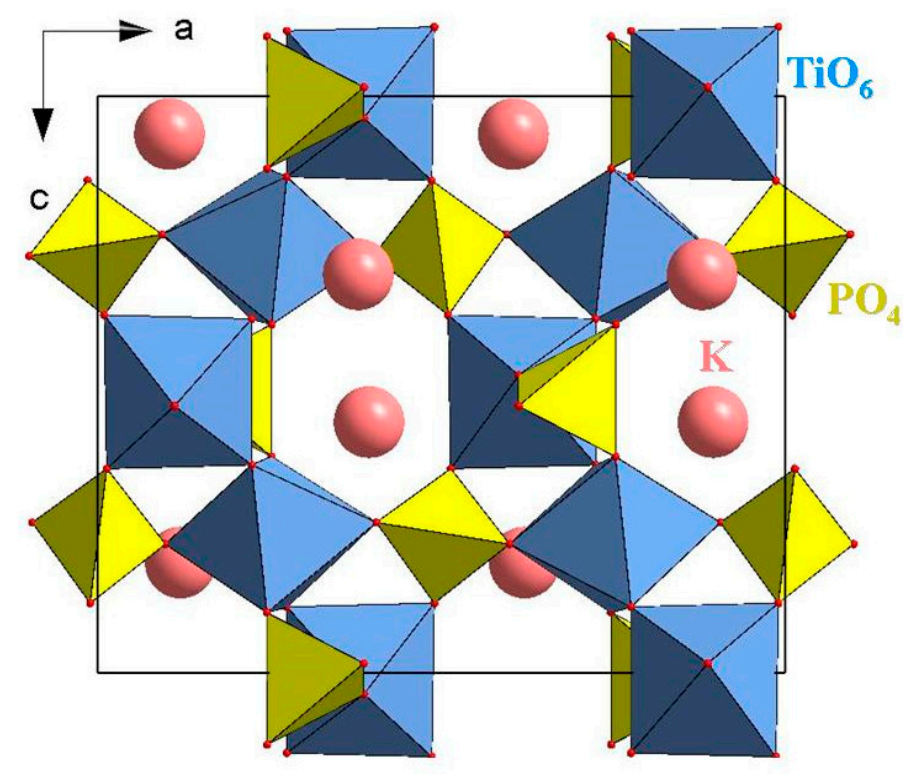

(a)

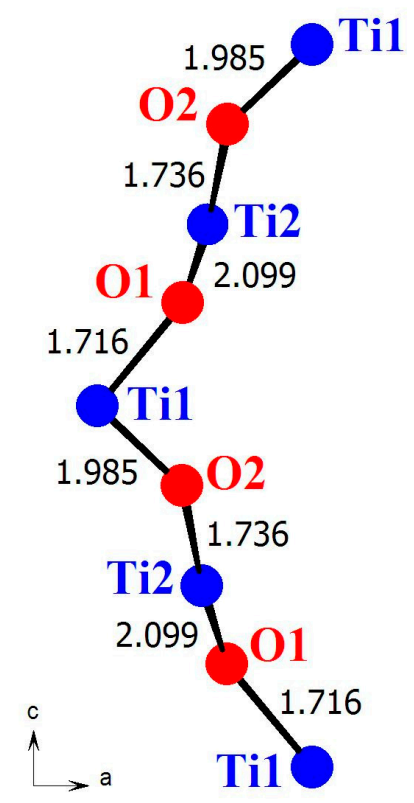

(b)

Figure 1. (a) Projection of the $\mathrm{KTiOPO}_{4}$ structure onto the (101) plane. (b) Alternation of Ti-O bond lengths $(\AA)$ in chains of $\mathrm{TiO}_{6}$ octahedra in the KTP structure: the $\mathrm{O} 1$ and $\mathrm{O} 2$ atoms occupy cis positions in the $\mathrm{Ti}_{1} \mathrm{O}_{6}$ octahedron and trans positions in the $\mathrm{Ti}_{2} \mathrm{O}_{6}$ octahedron.

Until recently, the nonlinear optical susceptibility of KTP crystals was associated with the alternation of long and short $\mathrm{Ti}-\mathrm{O}$ bonds in the chains of $\mathrm{TiO}_{6}$ octahedra (Figure $1 \mathrm{~b}$ ) resulting in a non-uniform distribution of the electron density among these structural units. Such distribution creates anharmonicity in induced vibrations of atoms in a crystal exposed to a harmonic electromagnetic wave, and thereby the appearance of the nonlinear optical properties. The correlation between the SHG signal intensity and the anharmonicity of effective displacements of atoms in the octahedron chains can be clearly traced in continuous series of solid solutions $\mathrm{K}\left(\mathrm{Ti}_{1-x} \mathrm{Ge}_{x}\right) \mathrm{OPO}_{4}[19]$ and $\mathrm{K}\left(\mathrm{Ti}_{1-x} \mathrm{Sn}_{x}\right) \mathrm{OPO}_{4}$ [20]. The stronger the distortions in the octahedra, the higher the intensity of the SHG signal.

Sometimes, the intensity of SHG signal decreases in compounds with strongly distorted octahedra [2] (for example, in $\mathrm{NaTiOPO}_{4}$ with complete substitution of sodium for potassium). On the other hand, the optical nonlinearity of KTP crystals doped with zirconium [21] and of KTA crystals [22] is larger than that of crystals of pure KTP, but their octahedra are less distorted. Analyzing $\mathrm{AsO}_{4}$ tetrahedra, the authors of [22] noticed a decrease in the Ti-O-As angles by $2-5^{\circ}$ in comparison with the Ti-O-P angles in $\mathrm{PO}_{4}$ tetrahedra, but the existence of chains of $\mathrm{TiO}_{6}$ octahedra with alternating long and short Ti-O bonds in the structure was assumed to be the main reason for the high optical susceptibility of KTA crystals.

The study of the structure and distribution of the electron density in RTA crystals at $T=9.6 \mathrm{~K}$ and room temperature $[23,24]$ revealed asymmetric dipole-like peaks of electron density near the Ti and $\mathrm{Rb}$ atomic positions in the $c$ direction. The optical susceptibility of these crystals was attributed to 
the possible localization of the electron density, as well as to charge transfer along the Ti-O-Ti-O and Ti-O-As-O chains.

At the end of the 20th century, studies $[17,25,26]$ appeared in which the optical susceptibility of KTP crystals was associated with $\mathrm{PO}_{4}$ tetrahedra and $\mathrm{KO}_{8} / \mathrm{KO}_{9}$ groups. The authors of [25] calculated the polarizability of the bonds in each of the structural groups of many nonlinear optical compounds, taking into account the fact that each type of constituent chemical bond contributed to the total linearity and nonlinearity of the crystal. In both KTP and KTA compounds, the origin of nonlinearity was concluded to be $\mathrm{KO}_{x}(x=8,9)$ groups and $\mathrm{P}(\mathrm{As}) \mathrm{O}_{4}$ groups. The authors of [26] believed that a strong distortion of octahedra was a necessary, but not sufficient, condition for high nonlinearity in crystals of the KTP family. In the opinion of the authors of [27], one should not to confine oneself to analyzing only a part of the structure while neglecting the remaining atoms when studying the causes of nonlinear optical properties. The second harmonic generation was shown to be connected with the acentricity of the atomic structure as a whole in the course of theoretical study on the relation between the yield of the second harmonic of laser radiation and degree of centrosymmetricity of the electric potential function of the whole atomic structure of the KTP crystal [27].

In situ neutron powder diffraction analysis from 297 to 1358 K [28] indicated the largest average displacements of $\mathrm{K}^{+}$and $\mathrm{P}^{5+}$ cations during the transition from paraelectric (space group Pnna in the authors' set) to ferroelectric (space group $P n a 2_{1}$ ) phase. The average values of the displacements at $297 \mathrm{~K}$ were $0.16,-0.59,0.04$ and $0.14 \AA$ for $\mathrm{O}^{2-}, \mathrm{K}^{+}, \mathrm{Ti}^{4+}$, and $\mathrm{P}^{5+}$ ions, respectively. Total spontaneous polarization was estimated to be $-0.19 \mu \mathrm{C} \mathrm{cm}^{-2}$. Contributions of $\mathrm{O}^{2-}, \mathrm{K}^{+}, \mathrm{Ti}^{4+}$, and $\mathrm{P}^{5+}$ ions to the total spontaneous polarization were $-0.23,-0.087,0.016$ and $0.105 \mu \mathrm{C} \mathrm{cm}^{-2}$, respectively. The intensity of SHG decreases with increasing temperature [17], and the decrease in the spontaneous polarization with increasing temperature corresponds to the dependence of the SHG intensity on the temperature $\sim\left(1-T / T_{C}\right)^{0.5}$. Thus, the results of studying the paraelectric phase of KTP crystals also suggest that the $\mathrm{K}^{+}$and $\mathrm{P}^{5+}$ ions significantly affect the bond polarizability and consequently, the $\mathrm{PO}_{4}$ tetrahedra and the $\mathrm{KO}_{8} / \mathrm{KO}_{9}$ groups contribute to the nonlinear susceptibility of crystals of the KTP family. The results of a study of neutron total (Bragg and diffusion) scattering in KTP crystals [29] from room temperature to $900{ }^{\circ} \mathrm{C}$ additionally suggested that changes in the local arrangement of oxygen atoms around $\mathrm{Ti}^{4+}$ and the displacement of $\mathrm{K}^{+}$were the reasons for the SHG signal decrease with increasing temperature, and therefore, a significant part of the SHG effect came from potassium cations.

Recent publications with $a b$ initio computations for the electronic structure and nonlinear optical characteristics of KTP-type crystals [30-32] emphasized the distortion of $\mathrm{TiO}_{6}$ octahedra, originating the superior nonlinear optical properties of these crystals. The distorted octahedron allows the dipolar excited states to mix with the bonding electronic states producing a strong hyperpolarizability on the Ti-O bonds [30]. In [31], it was found that the band structure of KTP-type phosphate crystals was dominated by $\mathrm{Ti}$ and $\mathrm{O}$ states and weakly dependent on the nature of the alkali-site element. Thus, the nonlinear optical properties of KTP-type solid solutions should be weakly influenced by ion substitution at the alkali-site positions. The observed anisotropy in the linear optical susceptibilities [32] was shown to provide enhanced phase matching conditions for the second harmonic generation. The strongest contributions to optical dielectric constant peaks were found to be due to the inter-band transitions between the valence-band maximum and conduction-band minimum. These transitions are often originated from $\mathrm{O}-2 p$ to Ti-3d states.

To date, a large number of studies of the atomic structure of crystals of the KTP family have been conducted, some of them at the Institute of Crystallography [33]. These studies were quite high level, but in order to analyze the defect structure of single crystals and structural reasons for their physical properties, a new, accurate approach to data collection was needed. This approach was used in the study of the atomic structure of crystals of pure KTP [34], specially selected single crystals (KTA [35], KTP, doped with zirconium (KTP:Zr) [36], hafnium (KTP:Hf) [37], and niobium (KTP:Nb) [38]) whose nonlinear susceptibility was higher than that of KTP crystals. This review summarizes the results of those studies. 


\section{Materials and Methods}

\subsection{Single Crystals}

Single crystals of KTP [34], KTA [35], KTP:Zr [36], KTP:Hf [37], and KTP:Nb [38] were grown by one method (crystallization from flux) in two ways (either spontaneous formation of crystallization centers or top-seeded solution growth during slow cooling of saturated solution melts). Single crystals of KTP and KTA were grown with top-seeded solutions at the Ariel University Center of Samaria, Israel, and at Faculty of Science of the Hebrew University of Jerusalem, Israel, using the method in [39]. Single crystals of KTP, KTP:Zr, KTP:Hf, and KTP:Nb were grown by spontaneous flux crystallization at the Faculty of Physics of the Moscow State University, Russia, using the method in [40]. Thereby, the single crystals of such compositions were studied: $\mathrm{KTiOPO}_{4}(\mathrm{CSD}$ nos 418747 and 418748) [34], $\mathrm{KTiOAsO}_{4}$ (CSD nos 421396 and 421397) [35], $\mathrm{KTi}_{0.96} \mathrm{Zr}_{0.04} \mathrm{OPO}_{4}$ (KTP:4\%Zr) (CSD no. 419907) [36], $\mathrm{KTi}_{0.985} \mathrm{Hf}_{0.015} \mathrm{OPO}_{4}$ (KTP:1.5\%Hf) (CSD nos 421392 and 422170), $\mathrm{KTi}_{0.965} \mathrm{Hf}_{0.035} \mathrm{OPO}_{4}$ (KTP:3.5\%Hf) (CSD nos 421393 and 422171), $\mathrm{KTi}_{0.872} \mathrm{Hf}_{0.128} \mathrm{OPO}_{4}$ (KTP:12.8\%Hf) (CSD nos 421394 and 4212172) [15,37], $\mathrm{K}_{0.945} \mathrm{Ti}_{0.951} \mathrm{Nb}_{0.049} \mathrm{PO}_{5}(\mathrm{KTP}: 4 \% \mathrm{Nb})$ (CSD no. 431502), and $\mathrm{K}_{0.952} \mathrm{Ti}_{0.945} \mathrm{Nb}_{0.055} \mathrm{PO}_{5}$ (KTP:6\%Nb) (CSD no. 431503) [38].

Physical properties of single crystals grown by top-seeded solution method were studied at the Ariel University Center of Samaria using the technique in [41-43]. Physical properties of single crystals grown by spontaneous flux crystallization were studied at the Faculty of Physics of the Moscow State University jointly with the Karpov Institute of Physical Chemistry [33]. Ferroelectric, dielectric, and conductive properties are not discussed in this review. The concentration dependence of the intensity of the SHG signal from a YAG:Nd laser was studied $[10,14,15,44]$ with powders of crushed single crystals by a method close to the Kurtz-Perry method [45], the average grain size being about $3 \mu \mathrm{m}$. The intensity of the signal was compared with the intensity of the SHG signal in the standard sample of quartz of the same dispersion.

\subsection{Accurate X-ray Analysis}

X-ray experiments were carried out using four-circle automatic diffractometers with detectors of two different types: a point detector, which measures each reflection in order (CAD-4F Enraf-Nonius, Deloft, The Netherlands; Huber-5042, Rimsting, Germany); and a CCD detector, which produces a two-dimensional diffraction pattern (Xcalibur S CCD Oxford Diffraction). Using a diffractometer with a point detector makes it possible to measure the intensity of weak reflections more accurately, including wide-angle ones. The wide-angle reflections $\left(\sin \theta / \lambda>0.6-0.7 \AA^{-1}\right)$ are mainly caused by the scattering of X-rays by the inner-shell electrons of atoms, which are not strongly perturbed during the chemical bonding. Therefore, the inclusion of such reflections in the structure refinement is highly important and allows obtaining more precise thermal and positional parameters of atoms, not changed due to chemical bonding. The contribution of wide-angle reflections to X-ray diffraction data corresponds more to scattering by spherically symmetric atoms, which is one of the main approximations of X-ray diffraction analysis. In experiments with KTA at $30 \mathrm{~K}$ [35] and with KTP:Nb [38], the maximum values of $\sin \theta / \lambda$ were $1 \AA^{-1}$. In experiments with KTP doped with $1.5 \%$ and $3.5 \% \mathrm{Hf}$ [37] this values were $1.37 \AA^{-1}$, and in other cases they were $1.22 \AA^{-1}$.

\section{Single Crystals of Pure KTP}

The purpose of the accurate X-ray diffraction study of pure KTP single crystals grown by one method (crystallization from the solution in the melt) in two ways (the top-seeded solution growth and spontaneous flux crystallization) [34] was to obtain the most complete and precise data on their structure in order to first, evaluate how the growth conditions affect the structure of the KTP crystals and second, to use the obtained data in the further investigations of the structure of KTP crystals doped with isovalent or heterovalent impurities. An analysis of the results of the refinement of the structure of KTP single crystals grown by one method—but in different ways—made it possible to 
reveal similarities and differences in their structure. Similarities in the unit cell parameters and the average interatomic distances in the structures were found. Furthermore, the potassium sublattices in the crystals under investigation were characterized by a similar disordering (existence of additional $\mathrm{K}$ positions). Despite the similarity in crystal-chemical parameters, the distribution of the electron density in the crystals was different due to different numbers of defects in the crystal structures. On the whole, the analysis of the difference distribution of the electron density suggested that, compared to the crystals grown by the top-seeded solution method, the crystals grown through the spontaneous flux crystallization contained a larger number of defects. This was indicated by higher peaks of the residual electron density near cation positions and by the presence of a larger number of uninterpreted residual peaks in the difference electron density maps.

It should be noted that it was possible to perfectly analyze the distribution of potassium ions over the structure channels only due to the high quality of the experiments. A more detailed, in compared to [34], analysis of the distribution of the residual electron density near the potassium atom positions was carried out in [46]. In the case of top-seeded crystallization, the peaks $X^{\prime}$ and $X^{\prime \prime}$ (Figure 2) of the residual electron density $\Delta \varrho_{\max }=0.83,0.41$ and $0.76,0.47 \mathrm{e} \AA^{-3}$, respectively, were located at distances of $\sim 0.45$ and $0.43 \AA$ from the $\mathrm{K} 1$ ( $\mathrm{KO}_{8}$ groups) and $\mathrm{K} 2$ ( $\mathrm{KO}_{9}$ groups) atoms, respectively. In the case of spontaneous crystallization, analogous peaks were at distances of $\sim 0.45$ and $0.44 \AA$ and their heights were $\Delta \varrho_{\max }=0.88,0.46$ and $0.77,0.41 \mathrm{e} \AA^{-3}$, respectively.

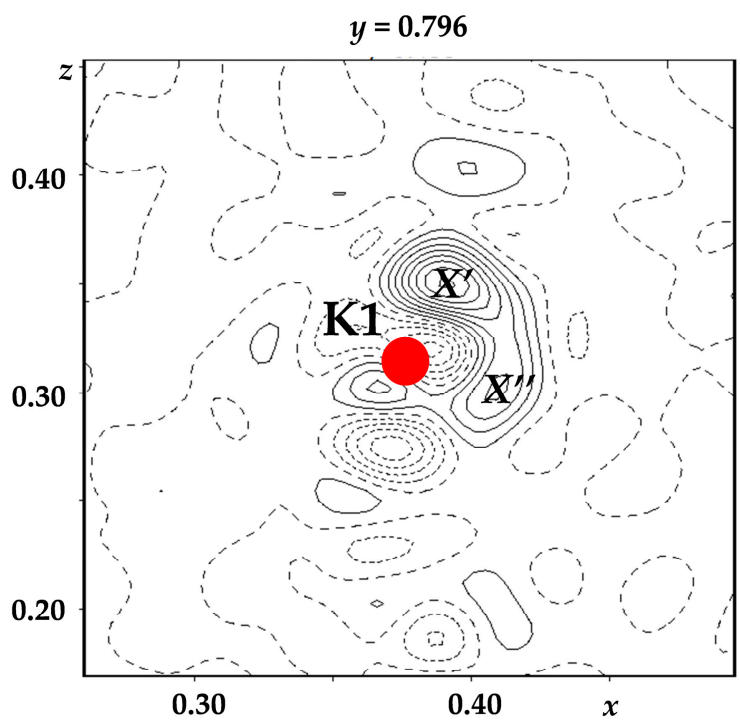

(a)

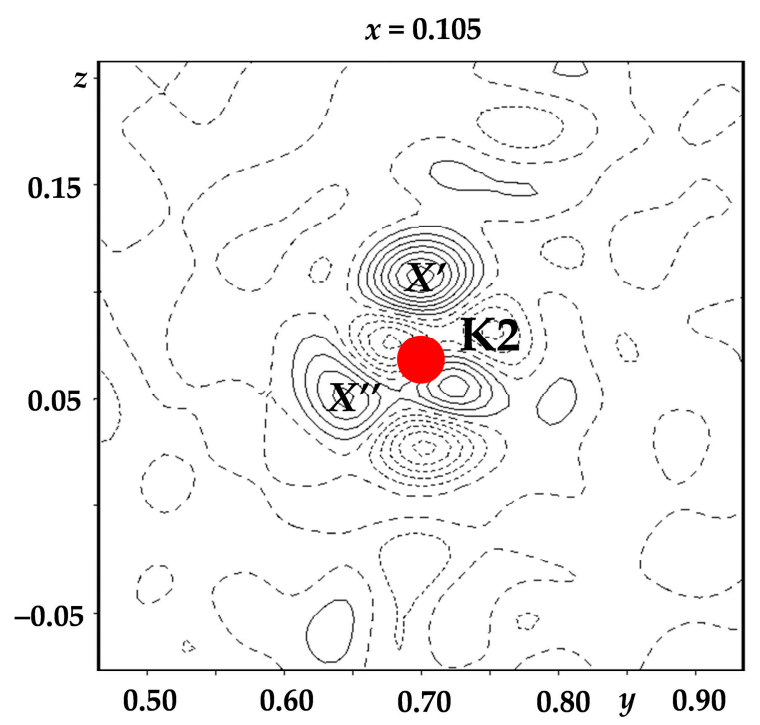

(b)

Figure 2. Difference maps of electron density near the positions: (a) of the K1 atom; (b) of the K2 atom for the crystal grown by the top-seeded solution method. The isolines are drawn in steps of $0.1 \mathrm{e} \AA^{-3}$.

In accordance with these peaks, the atoms $\mathrm{K}^{\prime}, \mathrm{K} 1^{\prime \prime}, \mathrm{K} 2^{\prime}$, and $\mathrm{K} 2{ }^{\prime \prime}$ were localized. The occupancies of the main and additional potassium positions were refined by the step-scan technique [47], which makes it possible to avoid a strong correlation between the atomic displacement parameters and the position occupancies. The final occupancies were assumed to be equal to the values corresponding to the midpoint of the confidence interval within which the discrepancy factor retained its minimum value. The error in the refinement was registered as equal to half the confidence interval. The occupancies of the main and additional positions of potassium atoms, as well as the distances between them, are listed in Table 1. 
Table 1. Occupancies of potassium atomic positions and distances between these positions in the structures of KTP single crystals.

\begin{tabular}{|c|c|c|c|c|c|c|}
\hline \multicolumn{7}{|c|}{ Occupancies of the Potassium Atomic Positions } \\
\hline Position & K1 & K1' & K1" & K2 & K2' & K2" \\
\hline $\mathrm{KTP}^{1}$ & $0.925(2)$ & $0.050(2)$ & $0.032(2)$ & $0.846(2)$ & $0.071(2)$ & $0.080(2)$ \\
\hline $\mathrm{KTP}^{2}$ & $0.838(1)$ & $0.092(1)$ & $0.058(1)$ & $0.843(2)$ & $0.061(2)$ & $0.090(2)$ \\
\hline \multicolumn{7}{|c|}{ Distances, Å } \\
\hline Positions & $\mathrm{K} 1-\mathrm{K} \mathbf{1}^{\prime}$ & $\mathrm{K} 1-\mathrm{K} 1^{\prime \prime}$ & $\mathrm{K} 2-\mathrm{K} 2^{\prime}$ & $\mathrm{K} 2-\mathrm{K} 2 "$ & $\mathrm{~K} \mathbf{1}^{\prime}-\mathrm{K} \mathbf{1}^{\prime \prime}$ & $\mathrm{K} 2^{\prime}-\mathrm{K} 2^{\prime \prime}$ \\
\hline $\mathrm{KTP}^{1}$ & $0.300(4)$ & $0.371(8)$ & $0.295(3)$ & $0.235(4)$ & $0.295(9)$ & $0.390(4)$ \\
\hline $\mathrm{KTP}^{2}$ & $0.284(3)$ & $0.277(6)$ & $0.321(3)$ & $0.246(4)$ & $0.286(5)$ & $0.414(4)$ \\
\hline
\end{tabular}

\section{Single Crystals of KTA}

KTA single crystals are of particular interest, as some of their nonlinear optical characteristics exceed those of KTP crystals and other members of this family. The intensity of the SHG signal increases by a factor of 1.6 in them [9]. KTA crystals hold the greatest promise for parametric light generation, because at wavelengths larger than $3 \mu \mathrm{m}$ they show a far weaker absorption than KTP crystals. The structure and properties of KTA single crystals have been studied over a wide temperature range, from room temperature to $725^{\circ} \mathrm{C}$ [48]. X-ray diffraction studies of KTA single crystals grown by the top-seeded solution method have been performed at 293 and $30 \mathrm{~K}$ [35].

\subsection{Changes in the Framework}

An analysis of the interatomic distances Ti-O and $\mathrm{P}(\mathrm{As})-\mathrm{O}$ and the degree of deviation from their mean values [35] showed that substituting arsenic atoms for smaller phosphorus atoms resulted in minor changes in the $\mathrm{TiO}_{6}$ octahedra. Note, however, a slightly (by $2 \%$ ) decreased difference in the Ti1-O2 and Ti1-O1 distances in the $\mathrm{Ti}_{1} \mathrm{O}_{6}$ octahedra (larger octahedra in comparison with $\mathrm{Ti}_{2} \mathrm{O}_{6}$ octahedra) and a slightly increased (by $\sim 1.5 \%$ ) difference in the corresponding distances in the $\mathrm{Ti}^{2} \mathrm{O}_{6}$ octahedra. Next, the junctions of $\mathrm{TiO}_{6}$ octahedra and $\mathrm{P}(\mathrm{As}) \mathrm{O}_{4}$ tetrahedra in the framework, that is, the $\mathrm{P}(\mathrm{As}) 2-\mathrm{O}-\mathrm{Ti1}-\mathrm{O}-\mathrm{P}(\mathrm{As}) 1, \mathrm{P}(\mathrm{As}) 2-\mathrm{O}-\mathrm{Ti2}-\mathrm{O}-\mathrm{P}(\mathrm{As}) 1$, Ti1-O-P(As)1-O-Ti2, and Ti1-O-P(As)2-O-Ti2 chains, were analyzed. In order to estimate relative changes in the Ti-O-P(As) chain links, the $\Delta$ parameter characterizing the degree of deviation of the difference of Ti-O and $\mathrm{P}(\mathrm{As})-\mathrm{O}$ interatomic distances from the difference of their average values was introduced. For Ti, $\mathrm{P}(\mathrm{As})$, and $\mathrm{O}$ atoms, forming the links of the Ti-O-P(As) chains, the $\Delta$ parameter was defined as

$$
\Delta=\frac{\left(d_{\mathrm{Ti}-\mathrm{O}}-d_{\mathrm{P}(\mathrm{As})-\mathrm{O}}\right)-\Delta_{0}}{\Delta_{0}},
$$

where $\Delta_{0}=d_{(\mathrm{Ti}-\mathrm{O}) \mathrm{av}}-d_{(\mathrm{P}(\mathrm{As})-\mathrm{O}) \mathrm{av}}$.

In the case of ideal structure the parameter $\Delta$ would be zero. But $\mathrm{TiO}_{6}$ octahedra and $\mathrm{PO}_{4}$ tetrahedra are distorted and this parameter is nonzero. The values of the parameter $\Delta$ for different Ti-O-P(As) links in the KTP and KTA structures are listed in Table 2.

In the Ti2-O5-P1, Ti1-O3-P1, and Ti1-O7-P2 links of the KTP structure (Figure 3), the degree of deviation from the difference of the average Ti-O and $\mathrm{P}(\mathrm{As})-\mathrm{O}$ interatomic distances is large: $\sim 16 \%, 44 \%$, and $17 \%$. The substitution of arsenic atoms for phosphorus atoms increased the degree of deviation from the difference of the average Ti-O and As-O interatomic distances almost in all Ti-O-As links (Table 2). 
Table 2. Degree of deviation $(\Delta)$ from the difference of the average Ti-O and $\mathrm{P}(\mathrm{As})-\mathrm{O}$ interatomic distances in the structures of KTP and KTA single crystals.

\begin{tabular}{ccc}
\hline Chemical Bonds & KTP & KTA \\
\hline Ti2-O6-P(As)1 & 0.0162 & 0.0275 \\
Ti2-O5-P(As)1 & 0.1582 & 0.1763 \\
Ti1-O4-P(As)1 & -0.0575 & -0.0711 \\
Ti1-O3-P(As)1 & 0.4427 & 0.6520 \\
Ti1-O7-P(As)2 & 0.1732 & 0.2354 \\
Ti1-O8-P(As)2 & 0.0555 & 0.1071 \\
Ti2-O9-P(As)2 & -0.0208 & -0.0553 \\
Ti2-O10-P(As)2 & 0.0491 & 0.0405 \\
\hline
\end{tabular}

The largest values of the $\Delta$ parameter $(\sim 18 \%, 65 \%$, and $24 \%)$ were found for the Ti2-O5-As1, Ti1-O3-As1, and Ti1-O7-As2 links. Similarly to the difference in the alternating short and long Ti-O distances in the chains of octahedra, the difference in the Ti-O and $\mathrm{P}(\mathrm{As})-\mathrm{O}$ interatomic distances results in a nonuniform distribution of the electron density over these fragments of the framework. The nonuniformity of the electron density distribution was confirmed by an analysis of the $\mathrm{P}(\mathrm{As})-\mathrm{O}-\mathrm{Ti}$, $\mathrm{Ti}-\mathrm{O}-\mathrm{Ti}$, and $\mathrm{O}-\mathrm{Ti}-\mathrm{O}$ angles [35]. When arsenic substituted for phosphorus in the structure, the angles change was $2-5.5^{\circ}$ : all the As-O-Ti angles decreased in relation to the $\mathrm{P}-\mathrm{O}-\mathrm{Ti}$ angles, whereas the $\mathrm{Ti}-\mathrm{O}-\mathrm{Ti}$ and $\mathrm{O}-\mathrm{Ti}-\mathrm{O}$ angles increased; i.e., the chains of $\mathrm{TiO}_{6}$ octahedra "straightened", while the As-O-Ti-O-As and Ti-O-As-O-Ti chains, on the contrary, "bent".

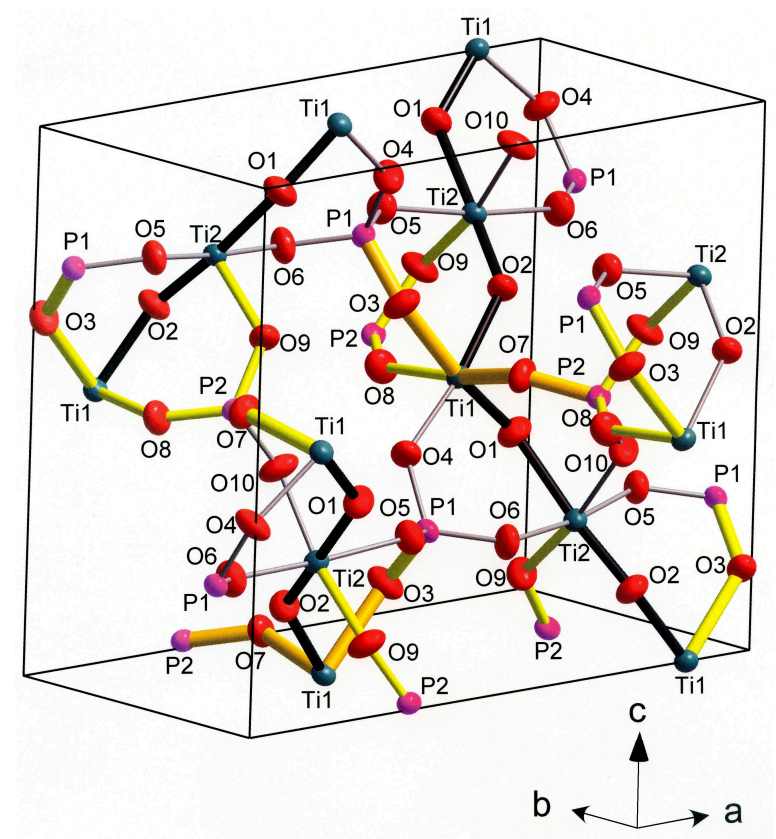

Figure 3. Structure of KTP single crystals (ellipsoids of atomic displacements are drawn at the $50 \%$ probability level): the black lines are Ti1-O1-Ti2-O2-Ti1 chains; the yellow lines show P2-O-Ti1-O-P1 and Ti1-O-P2-O-Ti2 chains in which the degree of deviation from the difference of the average Ti-O and $\mathrm{P}-\mathrm{O}$ interatomic distances is maximal (the width of the lines depends on the $\Delta$ parameter).

A highly nonuniform distribution of the electron density over the junctions of $\mathrm{TiO}_{6}$ octahedra and $\mathrm{AsO}_{4}$ tetrahedra in the KTA structure as compared to the KTP structure can lead to the SHG signal multiplication in KTA crystals compared to KTP crystals, which is consistent with the measured values of the SHG signal for KTA and KTP crystals [9]. 


\subsection{Changes in the Channels}

A study of the structure of KTA single crystals at room temperature [35] and comparison with the structure of KTP single crystals [46] have found the difference maps of electron density near positions of potassium atoms in both KTA and KTP structures to be identical (Figure 2). Analysis of the splitting of potassium atom positions (Table 3) indicates a change in the occupancies of the main and additional positions in the structure of the KTA as compared to KTP crystals. In KTA single crystals, the occupancies of the main $\mathrm{K} 1$ and $\mathrm{K} 2$ positions decrease and the occupancies of the additional $\mathrm{K}^{\prime}{ }^{\prime}, \mathrm{K} 1^{\prime \prime}, \mathrm{K} 2^{\prime}$, and $\mathrm{K} 2{ }^{\prime \prime}$ positions increase; i.e., the disordering of the $\mathrm{K} 1$ and $\mathrm{K} 2$ atoms in the KTA structure is somewhat greater (especially of the K1 atoms) than in the KTP structure, but the distances between the main and additional positions in both structures are comparable.

Table 3. Occupancies of potassium atomic positions and distances between these positions in the structure of KTP and KTA single crystals.

\begin{tabular}{|c|c|c|c|c|c|c|}
\hline \multicolumn{7}{|c|}{ Occupancies of the Potassium Atomic Positions } \\
\hline Position & K1 & $\mathrm{K1}^{\prime}$ & K1" & K2 & K2' & K2" \\
\hline KTP & $0.925(2)$ & $0.050(2)$ & $0.032(2)$ & $0.846(2)$ & $0.071(2)$ & $0.080(2)$ \\
\hline KTA & $0.865(7)$ & $0.087(5)$ & $0.043(8)$ & $0.820(9)$ & $0.089(8)$ & $0.088(8)$ \\
\hline \multicolumn{7}{|c|}{ Distances, Å } \\
\hline Positions & $\mathrm{K} 1-\mathrm{K}^{\prime}$ & K1-K1" & $\mathrm{K} 2-\mathrm{K} 2^{\prime}$ & $\mathrm{K} 2-\mathrm{K} 2 "$ & $\mathrm{~K} 1^{\prime}-\mathrm{K} 1^{\prime \prime}$ & $\mathrm{K} 2^{\prime}-\mathrm{K} 2^{\prime \prime}$ \\
\hline КТР & $0.300(4)$ & $0.371(8)$ & $0.295(3)$ & $0.235(4)$ & $0.295(9)$ & $0.390(4)$ \\
\hline KTA & $0.295(5)$ & $0.372(7)$ & $0.303(5)$ & $0.218(6)$ & $0.262(7)$ & $0.408(9)$ \\
\hline
\end{tabular}

At $30 \mathrm{~K}$, the patterns of the electron density distribution near the potassium atomic positions in the structure of the KTA change. Near the position K1, the peak $X^{\prime}$ of the electron density (Figure 2), corresponding to the atom $\mathrm{K}^{\prime}{ }^{\prime}$ at room temperature, disappears. At a distance of $\sim 0.51 \AA$ the peak $X^{\prime \prime}$ of 0.41 e $\AA^{-3}$ in height, corresponding to the K1" atom at room temperature, remains. Near the K2 position at a distance of $\sim 0.56 \AA$, the peak $X^{\prime}$ (K2' position) is $0.41 \mathrm{e}^{-3}$ (it is likely to disappear

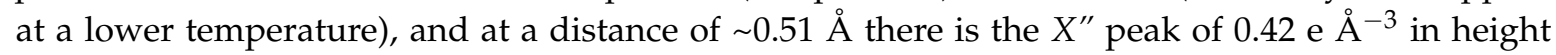
(K2" position). The disappearance of the $X^{\prime}$ peak near the $\mathrm{K} 1$ atomic position and the reduced height of the peak near the $\mathrm{K} 2$ atom indicate the dynamic disordering of potassium atoms at room temperature (anharmonicity of atomic displacements). Similar maps were observed for KTP crystals studied at 297, 100, and $9 \mathrm{~K}$ [49] (at $100 \mathrm{~K}$ a peak of lower intensity is still observed but at $9 \mathrm{~K}$ disappears). $X^{\prime \prime}$ peaks correspond to the static disordering of the potassium atoms, meaning these defects are formed during crystal growth.

Thus, the studies of KTA crystals [35] revealed a dynamic and static disordering of potassium atoms in the channels at room temperature. As compared to KTP crystals, the greater effect of static (greater occupancies of static positions) and dynamic (greater occupancies of dynamic positions) disordering of potassium atoms in the structure at room temperature enhances the nonuniformity of electron density distribution in the structure channels. This can also lead to an increase in the SHG signal.

\section{Single Crystals of KTP Doped with $\mathrm{Zr}$, Hf, and Nb}

KTP single crystals doped with $\mathrm{Zr}, \mathrm{Hf}$, and $\mathrm{Nb}$ were grown by spontaneous crystallization and studied in [36-38]. An increase in the SHG signal was observed at concentrations of these impurities $\sim 4-5 \%$.

\subsection{Changes in the Framework}

Impurities of $\mathrm{Zr}, \mathrm{Hf}$, and $\mathrm{Nb}$ replace Ti atoms in the KTP structure. Atoms of $\mathrm{Zr}(\sim 3 \%$ out of $4 \%$ ) and $\mathrm{Hf}(\sim 1.2 \%$ out of $1.5 \%, \sim 2.2 \%$ out of $3.5 \%$, and $\sim 9.5 \%$ out of $12.8 \%$ ) mainly occupy the 
$\mathrm{Ti} 2$ position (the $\mathrm{Ti}_{2} \mathrm{O}_{6}$ octahedron is smaller in volume and less distorted). Atoms of $\mathrm{Nb}$, on the other hand, replace Ti atoms mainly ( $3 \%$ out of $4 \%$ and $\sim 4 \%$ out of $6 \%$ ) in a larger $\mathrm{Ti}^{1} \mathrm{O}_{6}$ octahedron. The incorporation of $\mathrm{Zr}, \mathrm{Hf}$, and $\mathrm{Nb}$ atoms into the KTP structure and an increase in the impurity concentration leads to a decrease in the distortion of $(\mathrm{Ti1},(\mathrm{Zr}, \mathrm{Hf})) \mathrm{O}_{6}$, ( $(\mathrm{Ti} 2,(\mathrm{Zr}, \mathrm{Hf})) \mathrm{O}_{6}, \mathrm{TiO}_{6}$, and $\mathrm{NbO}_{6}$ octahedra (Table 4) and do not significantly affect the structure of $\mathrm{PO}_{4}$ tetrahedra [36-38]. Thus, the nonlinear susceptibility arising due to the difference in long and short bonds $(\mathrm{Ti},(\mathrm{Zr}, \mathrm{Hf}))-\mathrm{O}$ and $\mathrm{Ti}-\mathrm{O}$, $\mathrm{Nb}-\mathrm{O}$ decreases. However, in KTP crystals doped with hafnium, the SHG signal increases by $35-40 \%$ compared to KTP crystals [15], in crystals doped with niobium by $10-20 \%$ [10-12] and in crystals of KTP doped with zirconium it is almost doubled [13,14].

Table 4. Difference of lengths of titanyl bonds in the structures of pure KTP [46], KTP:4\%Zr [36], KTP:1.5\%Hf, KTP:3.5\%Hf, KTP:12.8\%Hf [37], KTP:4\%Nb, and KTP:6\%Nb [38].

\begin{tabular}{cccccccc}
\hline Bonds & KTP & $\begin{array}{c}\text { KTP: } \\
\mathbf{4 \% Z r}\end{array}$ & $\begin{array}{c}\text { KTP: } \\
\mathbf{1 . 5 \% H f}\end{array}$ & $\begin{array}{c}\text { KTP: } \\
\mathbf{3 . 5 \% H f}\end{array}$ & $\begin{array}{c}\text { KTP: } \\
\mathbf{1 2 . 8 \% H f}\end{array}$ & $\begin{array}{c}\text { KTP: } \\
\mathbf{4 \% N b}\end{array}$ & $\begin{array}{c}\text { KTP: } \\
\mathbf{6 \%} \mathbf{N b}\end{array}$ \\
\hline$\Delta_{\mathrm{Ti} 1-\mathrm{O} 2-\mathrm{Ti} 1-\mathrm{O} 1}$ & $0.2563(4)$ & $0.2430(5)$ & $0.2476(5)$ & $0.2416(6)$ & $0.2004(6)$ & $0.2312(8)$ & $0.2388(7)$ \\
& $(100 \%)$ & $(-5.2 \%)$ & $(-3.4 \%)$ & $(-5.7 \%)$ & $(-21.8 \%)$ & $(-9.8 \%)$ & $(-6.8 \%)$ \\
$\Delta_{\mathrm{Ti} 2-\mathrm{O} 1-\mathrm{Ti} 2-\mathrm{O} 2}$ & $0.3479(4)$ & $0.3298(5)$ & $0.3263(5)$ & $0.3178(6)$ & $0.2520(6)$ & $0.3348(5)$ & $0.3361(5)$ \\
$\Delta_{\mathrm{Nb} 1-\mathrm{O} 2-\mathrm{Nb} 1-\mathrm{O} 1}$ & $(100 \%)$ & $(-5.2 \%)$ & $(-6.2 \%)$ & $(-8.7 \%)$ & $(-27.6 \%)$ & $(-3.7 \%)$ & $(-3.4 \%)$ \\
$\Delta_{\mathrm{Nb} 2-\mathrm{O} 1-\mathrm{Nb} 2-\mathrm{O} 2}$ & - & - & - & - & - & $0.114(5)$ & $0.093(4)$ \\
\hline
\end{tabular}

As in KTA crystals [35], relative changes in the links of Ti-O-P chains, i.e., parameter $\Delta$ (1), were analyzed in [36-38]. This parameter did not change significantly and even decreased (Table 5) and the nonuniformity of the electron density distribution over these fragments of the framework decreased. Thus, the nonlinear susceptibility arising due to the difference in interatomic distances ( $\mathrm{Ti},(\mathrm{Zr}, \mathrm{Hf}))-\mathrm{O}$ and $\mathrm{P}-\mathrm{O}, \mathrm{Ti}-\mathrm{O}, \mathrm{Nb}-\mathrm{O}$ and $\mathrm{P}-\mathrm{O}$ decreased. The absence of significant changes in the structure of the KTP doped with zirconium, hafnium, and niobium was confirmed by an analysis of P-O-Ti, $\mathrm{Ti}-\mathrm{O}-\mathrm{Ti}$, and $\mathrm{O}-\mathrm{Ti}-\mathrm{O}$ angles. The variation of these angles was insignificant, $0.2^{\circ}-0.7^{\circ}$ on average.

Table 5. Degree of deviation $(\Delta)$ from the difference of the average Ti-O and $\mathrm{P}(\mathrm{As})-\mathrm{O}$ interatomic distances in the structures of pure KTP [46], KTP:4\%Zr [36], KTP:1.5\%Hf, KTP:3.5\%Hf, KTP:12.8\%Hf [37], KTP:4\%Nb, and $\mathrm{KTP}: 6 \% \mathrm{Nb}$ [38].

\begin{tabular}{cccccccc}
\hline Bonds & KTP & $\begin{array}{c}\text { KTP: } \\
\mathbf{4 \% \mathbf { Z r }}\end{array}$ & $\begin{array}{c}\text { KTP: } \\
\mathbf{1 . 5 \% H f}\end{array}$ & $\begin{array}{c}\text { KTP: } \\
\mathbf{3 . 5 \%} \mathbf{H f}\end{array}$ & $\begin{array}{c}\text { KTP: } \\
\mathbf{1 2 . 8} \mathbf{H} \mathbf{H f}\end{array}$ & $\begin{array}{c}\text { KTP: } \\
\mathbf{4 \% \mathbf { N b }}\end{array}$ & $\begin{array}{c}\text { KTP: } \\
\mathbf{6 \%} \mathbf{N b}\end{array}$ \\
\hline Ti2-O6-P(As)1 & 0.0181 & 0.0169 & 0.0123 & 0.0140 & 0.0058 & 0.0154 & 0.0138 \\
Ti2-O5-P(As)1 & 0.1559 & 0.1540 & 0.1530 & 0.1563 & 0.1511 & 0.1559 & 0.1550 \\
Ti1-O4-P(As)1 & -0.0599 & -0.0384 & -0.0429 & -0.0419 & -0.0075 & -0.0410 & -0.0449 \\
Ti1-O3-P(As)1 & 0.4445 & 0.4347 & 0.4367 & 0.4275 & 0.4045 & 0.4237 & 0.4265 \\
Ti1-O7-P(As)2 & 0.1787 & 0.1695 & 0.1622 & 0.1673 & 0.1721 & 0.1726 & 0.1583 \\
Ti1-O8-P(As)2 & 0.0510 & 0.0517 & 0.0529 & 0.0518 & 0.0541 & 0.0533 & 0.0640 \\
Ti2-O9-P(As)2 & -0.0218 & -0.0194 & -0.0139 & -0.0211 & -0.0216 & -0.0112 & -0.0072 \\
Ti2-O10-P(As)2 & 0.0507 & 0.0475 & 0.0425 & 0.0647 & 0.0406 & 0.0412 & 0.0418 \\
\hline
\end{tabular}

\subsection{Changes in the Channels}

The incorporation of $\mathrm{Zr}, \mathrm{Hf}$, and $\mathrm{Nb}$ atoms into the KTP structure resulted in significant changes in the channels [36-38]. In KTP:Zr [36] and KTP:Hf [37] crystals, the potassium atoms shifted relative to their main and additional positions in the KTP structure; occupancies of the main positions of potassium atoms decreased as compared with the KTP crystal, and the occupancies of the additional positions increased (Table 6). The distribution of potassium atom positions over the channels of the structures of these crystals was similar to the distribution in the KTP structure (Figure 4a). 
Table 6. Occupancies of potassium atomic positions and distances between these positions in the structure of pure KTP [46], KTP:4\%Zr [36], KTP:1.5\%Hf, KTP:3.5\%Hf, KTP:12.8\%Hf [37], KTP:4\%Nb, and $\mathrm{KTP}: 6 \% \mathrm{Nb}[38]$.

\begin{tabular}{|c|c|c|c|c|c|c|c|}
\hline \multicolumn{8}{|c|}{ Occupancies of the Potassium Atomic Positions } \\
\hline Position & K1 & $\mathbf{K} \mathbf{1}^{\prime}$ & K1" & K2 & K2' & K2" & K3 \\
\hline КTP & $0.838(1)$ & $0.092(1)$ & $0.058(1)$ & $0.843(2)$ & $0.061(2)$ & $0.090(2)$ & - \\
\hline KTP:4\%Zr & $0.770(4)$ & $0.135(6)$ & $0.091(6)$ & $0.722(6)$ & $0.146(6)$ & $0.126(7)$ & - \\
\hline KTP:1.5\%Hf & $0.863(7)$ & $0.080(7)$ & $0.050(7)$ & $0.851(9)$ & $0.080(9)$ & $0.060(8)$ & - \\
\hline KTP:3.5\%Hf & $0.823(3)$ & $0.099(3)$ & $0.080(3)$ & $0.817(2)$ & $0.090(2)$ & $0.087(2)$ & - \\
\hline KTP:12.8\%Hf & $0.869(2)$ & $0.078(2)$ & $0.040(2)$ & $0.845(2)$ & $0.080(2)$ & $0.059(2)$ & - \\
\hline KTP:4\%Nb & $0.827(2)$ & $0.052(2)$ & $0.037(2)$ & $0.827(4)$ & $0.058(4)$ & $0.036(4)$ & $0.053(2)$ \\
\hline KTP:6\%Nb & $0.734(4)$ & $0.187(5)$ & - & $0.670(5)$ & $0.146(4)$ & $0.104(5)$ & $0.062(4)$ \\
\hline \multicolumn{8}{|c|}{ Distances, ̊̊ } \\
\hline Positions & $\mathrm{K} 1-\mathrm{K} \mathbf{1}^{\prime}$ & K1-K1" & $\mathrm{K} 2-\mathrm{K} 2^{\prime}$ & $\mathrm{K} 2-\mathrm{K} 2 "$ & $\mathrm{~K} 1^{\prime}-\mathrm{K} 1^{\prime \prime}$ & $\mathrm{K} 2^{\prime}-\mathrm{K} 2^{\prime \prime}$ & $\mathrm{K} 1-\mathrm{K}^{1}{ }^{1}$ \\
\hline KTP & $0.284(3)$ & $0.277(6)$ & $0.321(3)$ & $0.246(4)$ & $0.286(5)$ & $0.414(4)$ & - \\
\hline KTP:4\%Zr & $0.263(6)$ & $0.180(7)$ & $0.262(7)$ & $0.186(7)$ & $0.367(8)$ & $0.278(9)$ & - \\
\hline KTP:1.5\%Hf & $0.233(6)$ & $0.320(10)$ & $0.234(8)$ & $0.249(5)$ & $0.250(10)$ & $0.430(20)$ & - \\
\hline KTP:3.5\%Hf & $0.330(10)$ & $0.227(6)$ & $0.294(5)$ & $0.249(7)$ & $0.170(10)$ & $0.390(10)$ & - \\
\hline KTP:12.8\%Hf & $0.317(6)$ & $0.324(9)$ & $0.300(8)$ & $0.257(8)$ & $0.310(10)$ & $0.390(10)$ & - \\
\hline $\mathrm{KTP}: 4 \% \mathrm{Nb}$ & $0.416(4)$ & $0.456(8)$ & $0.439(5)$ & $0.379(7)$ & $0.456(8)$ & $0.656(8)$ & $1.614(5)$ \\
\hline $\mathrm{KTP}: 6 \% \mathrm{Nb}$ & $0.251(3)$ & - & $0.235(7)$ & $0.188(8)$ & - & $0.292(9)$ & $1.629(5)$ \\
\hline
\end{tabular}

\footnotetext{
${ }^{1}$ In the structure of $\mathrm{KTP}: \mathrm{Nb}$ [38] position $\mathrm{K} 3$ is closer to the atom $\mathrm{K} 1$. Other distances for $\mathrm{K} 3$ position: $\mathrm{K} 2-\mathrm{K} 3=2.528(5) \AA, \mathrm{K} 1^{\prime}-\mathrm{K} 3=1.209(7) \AA, \mathrm{K} 1^{\prime \prime}-\mathrm{K} 3=1.564(8) \AA, \mathrm{K} 2^{\prime}-\mathrm{K} 3=2.722(7) \AA$, and $\mathrm{K} 2{ }^{\prime \prime}-\mathrm{K} 3=2.162(8) \AA$ for KTP:4\%Nb; K2-K3 = 2.556(5) $\AA, \mathrm{K}^{\prime}-\mathrm{K} 3=2.499(8) \AA$, and K2" $-\mathrm{K} 3=2.374(9) \AA$ for $\mathrm{KTP}: 6 \% \mathrm{Nb}$.
}

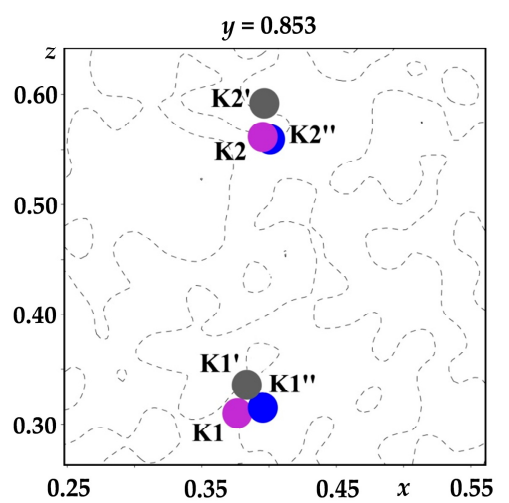

(a)

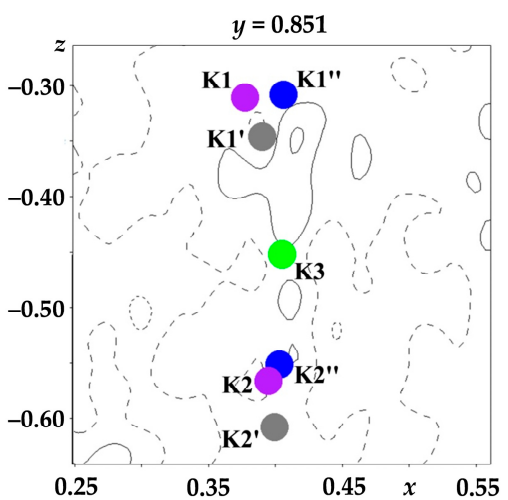

(b)

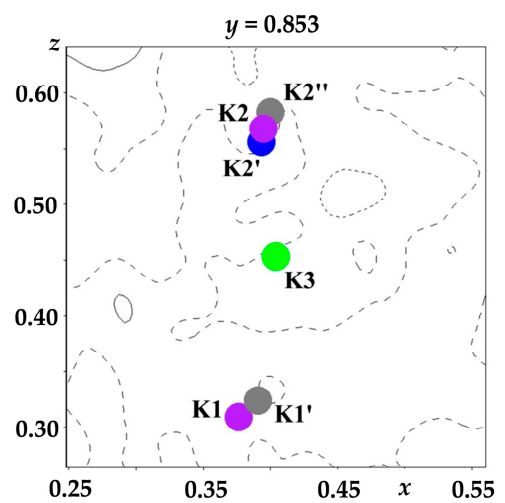

(c)

Figure 4. Difference maps of electron density in a channel after taking into account a statistical distribution of potassium atoms in the crystal structure of: (a) pure KTP [46]; (b) KTP:4\%Nb; (c) KTP:6\% $\mathrm{Nb}$ [38]. The isolines are drawn in steps of 0.1 e $\AA^{-3}$.

The largest displacements of the $\mathrm{K}^{\prime}$ and $\mathrm{K} 1^{\prime \prime}$ atoms for KTP:Hf crystals under study were observed in the $\mathrm{KTi}_{0.965} \mathrm{Hf}_{0.035} \mathrm{OPO}_{4}$ [37] in which the maximum SHG signal was detected. A similar situation was found in the crystal $\mathrm{KTi}_{0.96} \mathrm{Zr}_{0.04} \mathrm{OPO}_{4}$, in which the maximum SHG signal was also fixed. The decrease in the occupancies of the main potassium atom positions compared to the KTP crystal and the increase in the occupancies of the additional positions resulted in a redistribution of the electron density in the structure channels, namely, an increase in its concentration near the additional positions of the potassium atoms. The enhancement of the nonuniformity of the electron density distribution in the structure channels can result in increasing SHG signal in these crystals compared to KTP crystals. 
In the KTP:Nb crystals [38], the number of vacancies in the potassium sublattice rose with increasing $\mathrm{Nb}$ concentration. The occupancies of the main positions of the $\mathrm{K}$ atoms decreased (Table 6). The number of additional positions increased (a new position $\mathrm{K} 3$ appeared), and their location in the channels (Figure $4 \mathrm{~b}, \mathrm{c}$ ) and the distribution of $\mathrm{K}$ atoms over these positions changed.

The nonuniformity of the potassium distribution over its positions is more pronounced in the structure of the KTP: $4 \% \mathrm{Nb}$ crystal [38]. In this structure, additional atomic positions $\mathrm{K} 1^{\prime}, \mathrm{K} 1{ }^{\prime \prime}$ and $\mathrm{K}^{\prime}{ }^{\prime}, \mathrm{K} 2$ " are located farther from the main positions than in the KTP:6\% Nb crystal. On average, all additional positions are at distances of $\sim 0.4 \AA$ from each other and from the main positions, except for the $\mathrm{K} 3$ atom, which is located at a distance of $\sim 1.6 \AA$ from the atom K1 and $\sim 2.5 \AA$ from K2. With Nb concentration increasing to $\sim 6 \%$, the additional positions "approach" the main positions to distances of $\sim 0.2 \AA$, whereas the position of the $\mathrm{K} 3$ atom moves away from $\mathrm{K} 1$ and comes closer to the additional positions of the K2 atom. Such an arrangement of potassium atoms enhances the nonuniformity of electron density distribution in the channels of the structure and assures an enhancement of nonlinear optical properties, i.e., an increase in SHG signal.

\section{Conclusions}

Accurate X-ray diffraction analysis of KTP [34,46], KTA [35], KTP:Zr [36], KTP:Hf [37], and KTP:Nb [38] single crystals is carried out. In these crystals, the SHG signal of laser radiation is greater than in crystals of pure KTP. It is found that $\mathrm{TiO}_{6}$ octahedra, $\mathrm{PO}_{4}$ tetrahedra, $\mathrm{KO}_{8}$ groups, and $\mathrm{KO}_{9}$ groups contribute to the nonlinear optical properties of the KTP family crystals and the degree of contribution of each of the three structural components depends on the crystal composition. However, this is not the case for all compositions: the presence of alternating long and short Ti-O bonds in the chains of $\mathrm{TiO}_{6}$ octahedra is shown to be the decisive factor for the optical susceptibility of crystals.

Author Contributions: E.I.O. and V.I.V. grew crystals by the spontaneous flux crystallization method and studied physical properties of grown crystals; M.T. grew crystals by the top-seeded solution crystallization method and studied physical properties of grown crystals; I.A.V. performed the X-ray experiments; N.E.N., N.I.S., and O.A.A. carried out X-ray analysis; N.E.N., N.I.S., V.I.V., and M.T. wrote the paper.

Funding: This research received no external funding.

Acknowledgments: This work was supported by the Federal Agency of Scientific Organizations, agreement No 007-GZ/Ch3363/26.

Conflicts of Interest: The authors declare no conflicts of interest.

\section{References}

1. Zumsteg, F.G.; Bierlein, J.D.; Gier, T.E. $\mathrm{K}_{\mathrm{x}} \mathrm{Rb}_{1-\mathrm{x}} \mathrm{TiOPO}_{4}$ : A new nonlinear optical material. J. Appl. Phys. 1976, 47, 4980-4985. [CrossRef]

2. Stucky, G.D.; Phillips, M.L.F.; Gier, T.E. The potassium titanyl phosphate structure field: A model for new nonlinear optical materials. Chem. Mater. 1989, 1, 492-509. [CrossRef]

3. Hagerman, M.E.; Poeppelmer, K.R. Review of the structure and processing-defect-property relationships of potassium titanyl phosphate: A strategy for novel thin-film photonic devices. Chem. Mater. 1995, 7, 602-621. [CrossRef]

4. Satyanarayan, M.N.; Deepthy, A.; Bhat, H.L. Potassium titanyl phosphate and its isomorphs: Growth, properties, and applications. Crit. Rev. Solid State Mater. Sci. 1999, 24, 103-191. [CrossRef]

5. Fayaz, G.R.; Ghotbi, M.; Ebrahim-Zadeh, M. Efficient second-harmonic generation of tunable femtosecond pulses into the blue in periodically poled KTP. Appl. Phys. Lett. 2005, 86, 061110. [CrossRef]

6. Canalias, C.; Pasiskevicius, V.; Fokine, M.; Laurell, F. Backward quasi-phase-matched second-harmonic generation in submicrometer periodically poled flux-grown $\mathrm{KTiOPO}_{4}$. Appl. Phys. Lett. 2005, 86, 181105. [CrossRef] 
7. Fiorentino, M.; Kuklewicz, C.E.; Wong, F.N.C. Source of polarization entanglement in a single periodically poled $\mathrm{KTiOPO}_{4}$ crystal with overlapping emission cones. Opt. Express 2005, 13, 127-135. [CrossRef] [PubMed]

8. Roth, M.; Tseitlin, M. Growth of large size high optical quality KTP-type crystals. J. Cryst. Growth 2010, 312, 1059-1064. [CrossRef]

9. Bierlein, J.D.; Vanherzeele, H.; Ballman, A.A. Linear and nonlinear optical properties of flux-grown $\mathrm{KTiOAsO}_{4}$. Appl. Phys. Lett. 1989, 54, 783-785. [CrossRef]

10. Losevskaya, T.Y.; Alekseeva, O.A.; Yanovskii, V.K.; Voronkova, V.I.; Sorokina, N.I.; Simonov, V.I.; Stefanovich, S.Y.; Ivanov, S.A.; Eriksson, S.; Zverkov, S.A. Structure and properties of niobium-doped potassium titanil phosphate crystals. Crystallogr. Rep. 2000, 55, 739-743. [CrossRef]

11. Voronkova, V.I.; Yanovskii, V.K.; Losevskaya, T.Y.; Stefanovich, S.Y.; Zver'kov, S.A.; Alekseeva, O.A.; Sorokina, N.I. Electrical and nonlinear optical properties of $\mathrm{KTiOPO}_{4}$ single crystals doped with niobium, antimony, and tantalum. Crystallogr. Rep. 2004, 49, 123-129. [CrossRef]

12. Thomas, P.A.; Watts, B.E. An Nb-doped analogue of $\mathrm{KTiOPO}_{4}$; structural and nonlinear optical properties. Solid State Commun. 1990, 73, 97-100. [CrossRef]

13. Chani, V.I.; Shimamura, K.; Endo, S.; Fukuda, T. Growth of mixed crystals of the $\mathrm{KTiOPO}_{4}(\mathrm{KTP})$ family. J. Cryst. Growth 1997, 171, 472-476. [CrossRef]

14. Voronkova, V.I.; Yanovskii, V.K.; Leont'eva, I.N.; Agapova, E.I.; Kharitonova, E.P.; Stefanovich, S.Y.; Zver'kov, S.A. Growth and properties of Zr-doped $\mathrm{KTiOPO}_{4}$ crystals. Inorg. Mater. 2004, 40, 1321-1323. [CrossRef]

15. Orlova, E.I.; Kharitonova, E.P.; Novikova, N.E.; Verin, I.A.; Alekseeva, O.A.; Sorokina, N.I.; Voronkova, V.I. Synthesis, properties, and structure of potassium titanyl phosphate single crystals doped with hafnium. Crystallogr. Rep. 2010, 55, 404-411. [CrossRef]

16. Tordjman, I.; Masse, R.; Guitel, J.-C. Structure cristalline du monophosphate KTiPO 5 . Z. Kristallogr. 1974, 139, 103-115. [CrossRef]

17. Yanovskii, V.K.; Voronkova, V.I. Ferroelectric phase transitions and properties of crystals of $\mathrm{KTiOPO}_{4}$ family. Phys. Status Solidi 1986, 93, 665-668. [CrossRef]

18. Belokoneva, E.L.; Knight, K.S.; David, W.I.; Mill, B.V. Structural phase transitions in germanate analogues of $\mathrm{KTiOPO}_{4}$ investigated by high-resolution neutron powder diffraction. J. Phys. Condens. Matter 1997, 9 , 3833-3851. [CrossRef]

19. Sorokina, N.I.; Voronkova, V.I.; Yanovskii, V.K.; Verin, I.A.; Simonov, V.I. Crystal structures of compounds in the $\mathrm{KTiOPO}_{4}-\mathrm{KGeOPO}_{4}$ System. Crystallogr. Rep. 1996, 41, 432-435.

20. Krotova, O.D.; Sorokina, N.I.; Verin, I.A.; Voronkova, V.I.; Yanovskii, V.K.; Simonov, V.I. Structure and properties of single crystals of tin-doped potassium titanyl phosphate. Crystallogr. Rep. 2003, 48, 925-932. [CrossRef]

21. Alekseeva, O.A.; Dudka, A.P.; Sorokina, N.I.; Pietraszko, A.; Rabadanov, M.K.; Agapova, E.I.; Voronkova, V.I.; Simonov, V.I. Crystal structure of potassium titanyl phosphate doped with zirconium. Crystallogr. Rep. 1996, 41, 432-435. [CrossRef]

22. Mayo, S.C.; Thomas, P.A.; Teat, S.J.; Loiacono, G.M.; Loiacono, D.N. Structure and non-linear optical properties of $\mathrm{KTiOAsO}_{4}$. Acta Crystallogr. B 1994, 50, 655-662. [CrossRef]

23. Almgren, J.; Streltsov, V.A.; Sobolev, A.N.; Figgis, B.N.; Albertsson, J. Structure and electron density in $\mathrm{RbTiOAsO}_{4}$ at $9.6 \mathrm{~K}$. Acta Crystallogr. B 1999, 55, 712-720. [CrossRef] [PubMed]

24. Streltsov, V.A.; Nordborg, J.; Albertsson, J. Synchrotron X-ray analysis of $\mathrm{RbTiOAsO}_{4}$. Acta Crystallogr. B 2000, 56, 785-791. [CrossRef] [PubMed]

25. Xue, D.; Zhang, S. Chemical bond analysis of the correlation between crystal structure and nonlinear optical properties of complex crystals. Physica B 1999, 262, 78-83. [CrossRef]

26. Thomas, P.A.; Baldwin, A.; Dupree, R.; Blaha, P.; Schwarz, K.; Samoson, A.; Gan, Z.J. Structure-property relationships in the nonlinear optical crystal $\mathrm{KTiOPO}_{4}$ investigated using NMR and ab initio DFT calculations. J. Phys. Chem. B 2004, 108, 4324-4331. [CrossRef] 
27. Ivanov, V.A.; Burdov, V.A.; Marychev, M.O.; Titaev, D.N.; Faddeev, M.A.; Chuprunov, E.V. On the effect of structural and symmetrical features of potassium titanyl phosphate crystals with different contents of niobium, antimony, and zirconium on the second-harmonic intensity. Crystallogr. Rep. 2008, 53, 678-682. [CrossRef]

28. Yashima, M.; Komatsu, T. Order-disorder and displacive components in the ferroelectric-paraelectric phase transition of potassium titanyl phosphate $\mathrm{KTiOPO}_{4}$. Chem. Commun. 2009, 1070-1072. [CrossRef] [PubMed]

29. Norberg, S.T.; Thomas, P.A.; Tucker, M.G. A neutron total scattering study of local coordination in $\mathrm{KTiOPO}_{4}$ from room temperature to $900{ }^{\circ} \mathrm{C}$. J. Phys. Condens. Matter 2011, 23, 175401. [CrossRef] [PubMed]

30. Reshak, A.H.; Kityk, I.V.; Auluck, S. Investigation of the linear and nonlinear optical susceptibilities of $\mathrm{KTiOPO}_{4}$ single crystals: Theory and experiment. J. Phys. Chem. B 2010, 114, 16705-16712. [CrossRef] [PubMed]

31. Atuchin, V.V.; Kesler, V.G.; Meng, G.; Lin, Z.S. The electronic structure of $\mathrm{RbTiOPO}_{4}$ and the effect of the A-site cation substitution in $\mathrm{KTiOPO}_{4}$-family crystals. J. Phys. Condens. Matter 2012, 24, 45503. [CrossRef] [PubMed]

32. Ghoohestani, M.; Arab, A.; Hashemifar, S.J.; Sadeghi, H. Ab-initio investigation of Rb substitution in KTP single crystals. J. Appl. Phys. 2018, 123, 015702. [CrossRef]

33. Sorokina, N.I.; Voronkova, V.I. Structure and properties of crystals in the potassium titanyl phosphate family: A review. Crystallogr. Rep. 2007, 52, 80-93. [CrossRef]

34. Novikova, N.E.; Verin, I.A.; Sorokina, N.I.; Alekseeva, O.A.; Voronkova, V.I.; Tseitlin, M.; Roth, M. Structure of $\mathrm{KTiOPO}_{4}$ single crystals grown by the top-seeded solution and spontaneous flux crystallization methods. Crystallogr. Rep. 2008, 53, 942-951. [CrossRef]

35. Novikova, N.E.; Verin, I.A.; Sorokina, N.I.; Alekseeva, O.A.; Tseitlin, M.; Roth, M. Structure of $\mathrm{KTiOAsO}_{4}$ single crystals at 293 and $30 \mathrm{~K}$. Crystallogr. Rep. 2010, 55, 412-423. [CrossRef]

36. Novikova, N.E.; Verin, I.A.; Sorokina, N.I.; Alekseeva, O.A.; Agapova, E.I.; Voronkova, V.I. Structural reasons for the nonlinear optical properties of $\mathrm{KTi}_{0.96} \mathrm{Zr}_{0.04} \mathrm{OPO}_{4}$ single crystals. Crystallogr. Rep. 2009, 54, $219-227$. [CrossRef]

37. Novikova, N.E.; Verin, I.A.; Sorokina, N.I.; Alekseeva, O.A.; Orlova, E.I.; Voronkova, V.I. X-ray diffraction study of KTiOPO4 single crystals doped with hafnium. Crystallogr. Rep. 2011, 56, 411-419. [CrossRef]

38. Novikova, N.E.; Sorokina, N.I.; Alekseeva, O.A.; Verin, I.A.; Kharitonova, E.P.; Orlova, E.I.; Voronkova, V.I. Accurate X-ray diffraction studies of $\mathrm{KTiOPO}_{4}$ single crystals doped with niobium. Crystallogr. Rep. 2017, 62, 66-77. [CrossRef]

39. Roth, M.; Angert, N.; Tseitlin, M.; Alexandrovski, A. On the optical quality of KTP crystals for nonlinear optical and electro-optic applications. Opt. Mater. 2001, 16, 131-136. [CrossRef]

40. Voronkova, V.I.; Yanovskii, V.K. Growth of the $\mathrm{KTiOPO}_{4}$-group crystals from the solution in a melt and their properties. Inorg. Mater. 1988, 24, 205-208.

41. Angert, N.; Tseltlin, M.; Yashchin, E.; Roth, M. Ferroelectric phase transition temperatures of $\mathrm{KTiOPO}_{4}$ crystals grown from self-fluxes. Appl. Phys. Lett. 1995, 67, 1941-1943. [CrossRef]

42. Urenski, P.; Gorbatov, N.; Rosenman, G. Dielectric relaxation in flux-grown $\mathrm{KTiOPO}_{4}$ and isomorphic crystals. J. Appl. Phys. 2001, 89, 1850-1855. [CrossRef]

43. Tseitlin, M.; Mojaev, E.; Roth, M. Growth of high resestivity $\mathrm{RbTiOPO}_{4}$ crystals. J. Cryst. Growth 2008, 310 , 1929-1933. [CrossRef]

44. Voronkova, V.I.; Stefanovich, S.Y.; Yanovskii, V.K. Ferroelectric phase transitions and properties of nonlinear optical crystals of $\mathrm{KTiOPO}_{4}$ and its analogs. Sov. J. Quantum Electron. 1988, 18, 480-483. [CrossRef]

45. Kurtz, S.K.; Perry, T.T. A powder technique for the evaluation of nonlinear optical materials. J. Appl. Phys. 1968, 39, 3798-3813. [CrossRef]

46. Novikova, N.E. Structure and Pyroelectric Properties of Single Crystals of Potassium Titanyl Phosphate Family. Ph.D. Thesis, Shubnikov Institute of Crystallography of Russian Academy of Sciences, Moscow, Russia, 21 February 2012. (In Russian)

47. Muradyan, L.A.; Radaev, S.F.; Simonov, V.I. Accurate structural studies of crystals and correlation of refined parameters. In Methods of Structural Analysis; Nauka: Moscow, Russia, 1989; pp. 5-20, ISBN 5-02-000674-2. (In Russian) 
48. Northrup, P.A.; Parise, J.B.; Cheng, L.K.; Cheng, L.T.; McCarron, E.M. High-temperature single-crystal X-ray diffraction studies of potassium and (cesium, potassium) titanyl arsenates. Chem. Mater. 1994, 6, 434-440. [CrossRef]

49. Larsen, F.K. Diffraction studies of crystals at low temperatures-Crystallography bellow 77 K. Acta Crystallogr. B 1995, 51, 468-482. [CrossRef] 